\title{
A Gravimetric Approach for the Determination of Orthometric heights in Akure Environs, Ondo State, Nigeria
}

\author{
Tata, Herbert ${ }^{1 *}$ Matthew Nnonyelu Ono ${ }^{2}$ \\ 1. Department of Surveying and Geoinformatics, School of Environmental Technology, Federal University \\ of Technology Akure, Ondo State Nigeria. \\ 2. Department of Surveying and Geoinformatics, Faculty of Environmental Sciences Nnamdi Azikiwe \\ University Awka, Anambra State Nigeria. \\ *Email of the Corresponding Author: htata@futa.edu.ng or tataherbs@gmail.com
}

\begin{abstract}
An important component in position determination of any point is its height. Orthometric height determination has a significant role in geodesy, and it has wide-ranging application in numerous fields and activities. Orthometric height is the height above or below the geoid along the gravity plumb line. Orthometric height system is preferred to ellipsoidal height by many because of its relationship with the mean sea level (MSL). Determination of orthometric heights for Akure environs was carried out using gravimetric approach by determining geoidal undulations via Stokes integral and ellipsoidal heights via GPS observations. A total of 59 stations within the study area were occupied for gravity observation using Lacoste and Romberg (G-512 series) and its complete accessories. South GNSS instrument was used in static mode for position and ellipsoidal height determination. In order to determine orthometric heights of the study area, the difference between the tailored geoid height $\left(\mathrm{N}^{\text {Taylor }}\right)$ and the ellipsoidal heights $\left(\mathrm{h}_{\mathrm{GPS}}\right)$ were computed. The result shows that the determined orthometric heights have a standard deviation value as $10.6121 \mathrm{~m}$ with a standard error as $1.38159 \mathrm{~m}$. The contour map and the 3D surface map of the computed orthometric heights were produced for the study area. The study recommends the use of gravimetric method in orthometric height determination when the tailored geoid height is computed.
\end{abstract}

Keyword: Orthometric height, ellipsoidal height, gravity measurement, 3-D Surface Map

\section{Introduction}

An important component in position determination of any point is its height. Different height systems have been used depending on the reference surface and the method of its determination. Among these height systems are dynamic heights, orthometric heights, normal heights and geodetic heights. Of these, orthometric heights which are heights referred to mean sea level are very important practically because of their geocentric and physical significance. Orthometric heights are normally obtained from spirit levelling and gravity measurement (Moka, 2011).

Orthometric height determination has a significant role in geodesy, and it has wide-ranging applications in numerous fields and activities. Orthometric height is the height above or below the geoid along the gravity plumb-line (Peprah and Kumi, 2017). It is the distance, measured positive outwards or negative inwards along the plumb line, from the geoid (zero orthometric height) to a point of interest, usually on the topographic surface. The curved plumb line is at every point tangential to the gravity vector generated by the earth, its atmosphere and rotation. The orthometric height can be calculated from the geopotential number if obtainable, using the mean value of the earth's gravity acceleration along the plumb line between the geoid and the earth's surface (Peprah and Kumi, 2017).

One of the basic goals of geodesy is the determination of the geoid, which is the equipotential surface of the earth gravity field and which coincides on the average with the mean sea level (Hussein and Mahmood, 2016). Geoid surface is usually more irregular in shape than the ellipsoidal surface used in estimating the figure of the physical earth, but considerably smoother than the earth's physical surface. The conversion of ellipsoidal heights to orthometric heights entails that the geoid height refer to the same reference ellipsoid. In the case of GPS-derived ellipsoidal heights the geocentric WGS84 ellipsoid is used equation (1) (Husseinand Mahmood, 2016).

$\mathbf{H}=\mathbf{h}-\mathbf{N}$

Conventionally, terrestrial approaches for the production of elevation models include spirit levelling, tacheometry, and trigonometric surveys (using total stations) (Kavanagh, 2006). However these approaches that produce precise orthometric heights of points, are very tedious and require a lot of time when large expanse of land is to be surveyed (Uzodinma et al. 2014). Nevertheless, with the advent of GPS technology which is much faster and a more convenient method of deriving ellipsoidal heights, research attention has shifted to the precise determination of local, regional or global geoid models which are required for accurate geometric transformation of ellipsoidal heights to orthometric heights (Featherstone et al. 1998).

The method of obtaining orthometric height has been adopted by many nations around the world. This is because the approach is faster, less tedious in difficult terrain and relatively cheaper when compared to the geodetic leveling technique (Okeke and Nnam, 2016).

Depending on data availability and accuracy requirements, there are many principle approaches for determining geoid 
models; some of the approaches are gravimetric method, geometric method and the astro-geodetic method (Ono, 2009).

The gravimetric method is achieved by making gravity measurements and applying the Stoke's integral in the determination of a local and regional gravimetric geoid.

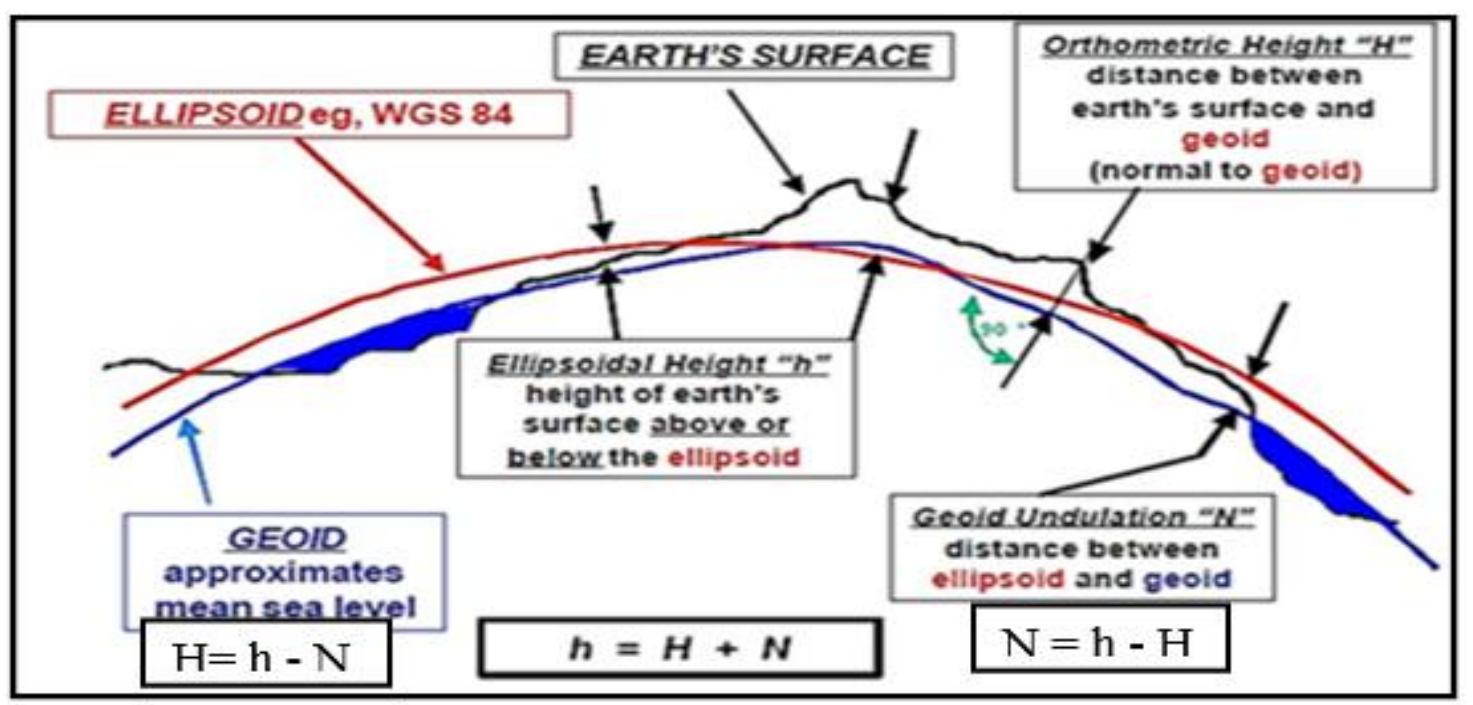

Figure1.The different surfaces and their heights (Amal, 2016)

\subsection{Gravimetric Geoid}

The word 'gravimetric' comes from gravity, which can be defined as the resultant effect of gravitation and centrifugal forces of rotating Earth (Heiskanen and Moritz, 1967; Fubara, 2007).

Gravimetric geoid is the oldest method of geoid determination. The principle of this method requires that the entire earth's surface be sufficiently and densely covered with gravity observations. Practically, a dense gravity net around the computation point and a reasonably uniform distribution of gravity measurement outside are sufficient. Then, gravity approximation is inevitable, so as to fill the gap with extrapolated values (Featherstone et al. 1998 and 2005).

Depending on area of coverage, gravimetric geoid may be global, regional, or local. Regional gravimetric geoid models are the best because they are of high resolution, local gravity and terrain data are often added to the global geopotential model and optimised for the area of interest (Featherstone et al. 1998 and 2005).

However, the application of this technique is mainly dependent on the availability of high-resolution gravity data. The original technique is based on Stoke's- Integral equation (2) 1and the use of accurately determined absolute gravity data (Heiskanen and Moritz, 1967).

$$
\begin{aligned}
& N=\frac{R}{4 \pi G} \iint_{\sigma} \Delta g S(\psi) d \sigma \\
& \text { where; } \\
& \iint_{\sigma}=\text { an integral extended over the whole Earth } \\
& R=\text { Mean radius of the Earth. } \\
& \mathrm{G}=\mathrm{G} \text { is the universal gravitational constant: } \\
& \mathrm{G}=6.673 \times 10^{-11} \mathrm{~ms}^{-2} \text { ( or } \mathrm{N} \mathrm{m}^{2} \mathrm{~kg}^{-2} \text { ), which has the same value for all pairs of particles. } \\
& \Delta \mathrm{g}=\text { Gravity anomaly known everywhere; on the Earth } \\
& \mathrm{S}(\psi)=\text { Stokes' function between the computation and integration points } \\
& \psi=\text { Spherical distance } \\
& \mathrm{d} \sigma=\text { Differential area on the geoid }
\end{aligned}
$$

The surface spherical radius, $\psi_{o}$ is computed as (Shrivastava et al, 2015)

$$
\cos \psi=\sin \varphi \sin ^{\prime}+\cos \varphi \cos \varphi^{\prime} \cos \left(\lambda^{\prime}-\lambda\right)
$$

where,

$\varphi \quad=$ latitude 1 of the compartment 


$$
\begin{aligned}
& \varphi^{\prime} \quad=\text { latitude } 2 \text { of the compartment } \\
& \lambda=\text { longitude } 1 \text { of the compartment } \\
& \lambda^{\prime}=\text { longitude } 2 \text { of the compartment } \\
& S(\psi)=\csc \left(\frac{\psi}{2}\right)-6 \sin \left(\frac{\psi}{2}\right)+1-5 \cos \psi-3 \cos \psi \ln \left\{\sin \left(\frac{\psi}{2}\right)+\sin ^{2}\left(\frac{\psi}{2}\right)\right\}
\end{aligned}
$$

Stokes's formula, as given in Equation (3), is often described as classical solution of the geodetic boundary value problem. It computes absolute geoid and requires data all over the Earth to compute geoidal undulation. This makes its application to be expensive, tedious and time consuming (Featherstone et al. 1998 and 2005).

\section{Overview of Study Area}

The study area selected for this research is Akure Environs figure 2 (A) of Ondo State in South-Western part of Nigeria, which covers an approximate area of $89 \mathrm{sqKm}$. The geographic location is approximately between latitudes $07^{\circ} 15^{\prime} \mathrm{N}$ and $07^{\circ} 30^{\prime} \mathrm{N}$ and between longitudes $05^{\circ} 15^{\prime} \mathrm{E}$ and $05^{\circ} 25^{\prime} \mathrm{E}$, within Akure South Local Government Areas of Ondo State. The topography of the Basement Complex terrain of Akure is generally undulating with a virtually rugged terrain consisting of hills and valleys with field recorded elevation varying between $330 \mathrm{~m}$ above mean sea level in the southwestern border (Nigeria Army barracks) and 399m in the north eastern border (Shagari Estate) (Michael and Franklin 2017).
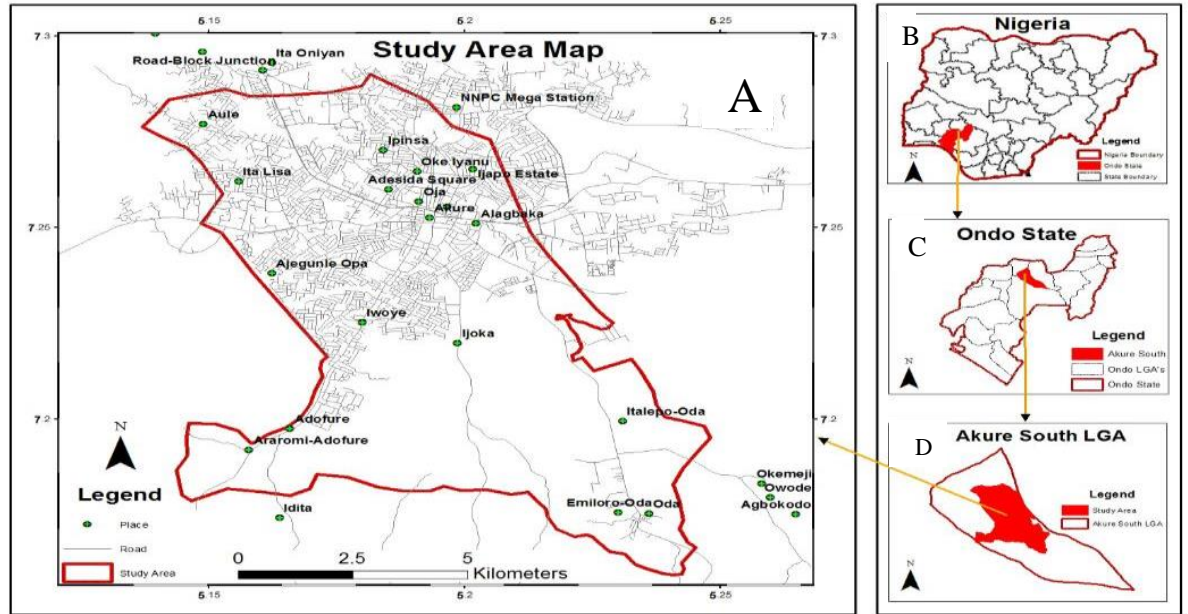

Figure2: Study area map (Akure Environs) (a) Nigeria Showing Ondo State (b)Administrative Map of Ondo showing Akure South (c) Map of Akure South Local Government (Source: Author, 2017).

\section{Methodology}

The gravimetric method of geoid determination was adopted for orthometric height computation in this study. A total of fifty nine (59) existing GPS stations within the study area were used for gravimetric observation. The gravity measurements were carried out by professionals from the National Geological Survey Agency (NGSA), Nigeria. A gravity base station at Akure Post Office was used as well as the base station at the Saint Peter's College Akure as control points. A Lacoste and Romberg (G-512 series) gravimeter was used to measure the gravity values of all the fifty nine (59) stations. South GNSS instrument, with its complete accessories was used in static mode for the determination of the positions and ellipsoidal heights of each of the points. The common corrections needed in a gravity survey such as the corrections for latitude, drift corrections, tide, free air, and Bouguer corrections were all applied accordingly for a better result. Using international gravity formula of geodetic system 1930 for normal gravity computation Equation (5), gravity anomaly for each of the observed point within the study area was computed.

$\Upsilon_{\mathrm{o}}=9.78049\left(1+0.0052884 \sin ^{2} \varphi-0.0000059 \sin ^{2} 2 \varphi\right) \mathrm{m} \cdot \mathrm{s}^{-2}$.

This formula is to augment the computation of gravity anomaly required as key input for assessing Stokes integral Equation 3 .

Gravity anomaly data obtained from the gravimetric observations and computations were used in the evaluation of geoidal undulations (N) using Stokes formula in a Microsoft Excel spread sheet program developed for this study. In the computation of gravimetric geoid, the entire study area was subdivided into different compartments of grid line of 1'x1' (1800 x 1800) $\mathrm{m}^{2}$. The subdivision was achieved by grid line of a fixed coordinate system $(\varphi, \lambda)$ forming square blocks. Hence the orthometric heights of the fifty nine (59) stations were determined by computing the differences between the ellipsoidal heights (h) and the geoidal heights $(\mathrm{N})$. 
In order to obtain a better fitting geoid, the gravimetric geoid is tailored to fit the local geoid. This is done by computing the differences between the gravimetric geoid and GPS/Levelling geoid and then fitting a surface to these differences through gridding as computed by (Moka, 2011). This is expressed mathematically as:

$\varepsilon=\mathrm{N}^{\mathrm{GPS}}-\mathrm{N}^{\mathrm{Grav}}$

and then

$\mathrm{N}^{\text {Taylor }}=\mathrm{N}^{\text {Grav }}+\varepsilon^{\text {grid }}$

The tailored geoid heights model was applied in equation (1) to obtain a fairly good fit that yielded acceptable orthometric heights.

\section{Results and Discussions}

This study was able to determine orthometric heights as shown in table 1. A data bank of the fifty nine (59) stations within the study area, with their longitude, latitudes, Gravity anomaly, Ellipsoidal Heights, Gravimetric Geoid and Orthometric Heights (Figures $3-6$ ) was created. The dataset presented in this study are extract of the full dataset of the ongoing research.

Table 1: Ellipsoidal heights derived from GNSS data, orthometric heights derived from gravimetric geoid and Akure gravimetric geoid height model derived from Stokes Integral

\begin{tabular}{|c|c|c|c|c|c|c|}
\hline Stations & $\begin{array}{c}\text { Latitude } \\
{\left[{ }^{\circ}\right]}\end{array}$ & $\begin{array}{c}\text { Longitude } \\
{\left[{ }^{\circ}\right]}\end{array}$ & $\begin{array}{c}\text { Gravity } \\
\text { anomaly, } \\
\Delta \mathrm{g})[\mathrm{m} / \mathrm{s}]\end{array}$ & $\begin{array}{c}\text { Observed } \\
\text { ellipsoidal } \\
\text { height (h) }[\mathrm{m}]\end{array}$ & $\begin{array}{c}\text { Akure gravimetric } \\
\text { geoid height derived } \\
\text { from Stokes Integral (N } \\
\text { GRAV) [m] }\end{array}$ & $\begin{array}{l}\text { Orthometric height }(\mathrm{H}) \\
{[\mathrm{m}]} \\
\left(\mathrm{H}_{\mathrm{GPS} / \mathrm{GRAV}}=\mathrm{h}_{\mathrm{GPS}}-\right. \\
\left.\mathrm{N}_{\mathrm{GRAV}}\right)\end{array}$ \\
\hline GPSA72S & 7.2707993 & 5.1670482 & 0.00011681 & 359.9130 & 13.4430 & 346.4700 \\
\hline GPSA73S & 7.2707205 & 5.1651083 & 0.00011680 & 358.6052 & 13.6513 & 344.9539 \\
\hline GPSA75S & 7.2718627 & 5.162073 & 0.00011381 & 352.0484 & 13.9463 & 338.1021 \\
\hline GPSA76S & 7.2725468 & 5.1597576 & 0.00011676 & 350.3126 & 13.7726 & 336.5400 \\
\hline GPSA77S & 7.2737013 & 5.1568474 & 0.00009589 & 348.2843 & 14.1975 & 334.0868 \\
\hline GPSA78S & 7.2736669 & 5.1551974 & 0.00011677 & 351.0061 & 14.0918 & 336.9143 \\
\hline GPSA79S & 7.2743554 & 5.1527432 & 0.00007153 & 356.3205 & 13.5685 & 342.7520 \\
\hline GPSA80S & 7.2754062 & 5.150703 & 0.00001000 & 359.4789 & 14.1616 & 345.3173 \\
\hline FG28 & 7.2759909 & 5.1481422 & 0.00006759 & 359.5066 & 13.2755 & 346.2311 \\
\hline FG29 & 7.2769842 & 5.1466017 & 0.00006738 & 353.7181 & 13.4880 & 340.2301 \\
\hline GPSA81S & 7.2723335 & 5.1607864 & 0.00016226 & 351.9264 & 13.8976 & 338.0288 \\
\hline GPSA82S & 7.2702406 & 5.1606406 & 0.00011675 & 347.8124 & 13.2327 & 334.5797 \\
\hline GPSA83S & 7.2615421 & 5.1625064 & 0.00012107 & 363.9258 & 14.1605 & 349.7653 \\
\hline GPSA84S & 7.258587 & 5.162796 & 0.00011673 & 360.0313 & 13.7050 & 346.3263 \\
\hline GPSA85S & 7.256818 & 5.1636238 & 0.00010889 & 353.4029 & 13.5549 & 339.8480 \\
\hline MEAN & & & 0.0006119 & 347.7476 & 13.2952 & 334.5032 \\
\hline STDEV & & & 4.2415 & 10.9589 & 0.6174 & 10.6121 \\
\hline RMS & & & 0.00061339 & 347.917 & 13.073599 & 334.669 \\
\hline
\end{tabular}

The gravity anomaly was computed by subtracting the normal gravity at the reference ellipsoid from the point gravity at the geoid as shown in equation (9)

$\Delta \mathrm{g}=\mathrm{g}_{\mathrm{p}}-\mathrm{Y}_{\mathrm{Q}}$

Where:

$$
\begin{aligned}
& \Delta \mathrm{g}=\text { gravity anomaly } \\
& \mathrm{g}_{\mathrm{p}}=\text { gravity at the Geoid } \\
& \Upsilon_{\mathrm{Q}}=\text { normal gravity at the reference ellipsoid }
\end{aligned}
$$

The Orthometric heights in Table1 were derived from the computed gravimetric geoid via Stokes integral and the ellipsoidal data were extracted from the processed GNSS observation using South GNSS processor software $\left(\mathrm{H}=\mathrm{h}_{\mathrm{GPS}}-\mathrm{N}_{\mathrm{GRAV}}\right)$. 


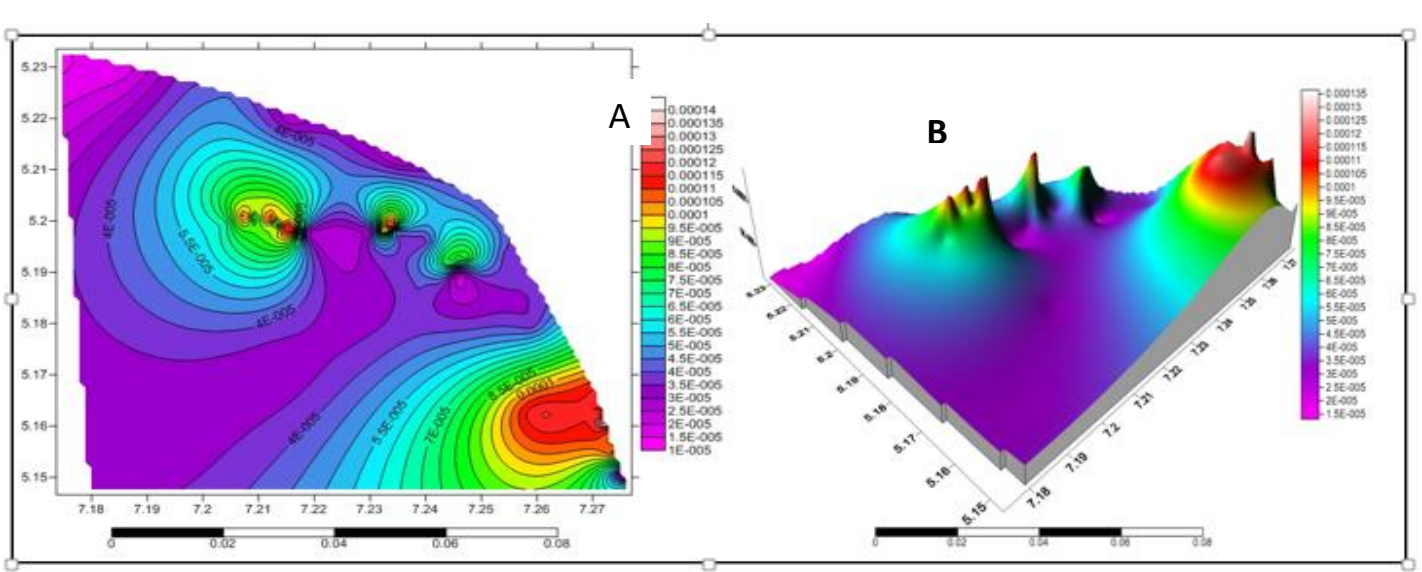

Figure3: Contour plot of gravity Anomaly (a) and surface plot (b)

Figure 3 (a) is a contour plot of gravity anomaly computed via the difference between gravity at the Geoid and normal gravity at the reference ellipsoid. The data in Table 1 were used for the plotting. The minimum and maximum contour values are 0.00001 and 0.00014 . The contour were plotted in Surfer 11 software, applying kriging gridding method at 0.000001 contour interval. Figure 3 (b) is the surface plot of Figure 3 (a) with minimum and maximum values as 0.00001 and 0.00014 respectively.

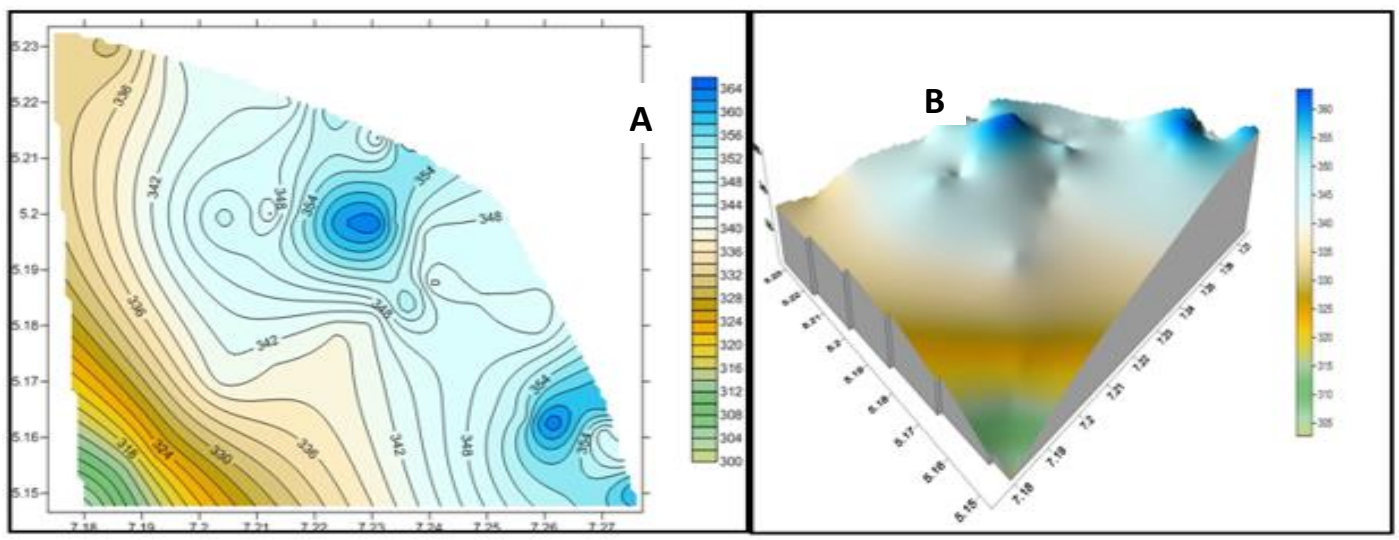

Figure 4: (a) contour plot and (b) DTM of ellipsoidal heights obtained from GNSS

Figure 4 (a) is the contour plot of ellipsoidal height obtained from the data set in table 1 . The minimum contour value is $300 \mathrm{~m}$ and the maximum value is $365 \mathrm{~m}$. The plotting was done in Surfer software using kriging gridding method at $2 \mathrm{~m}$ grid interval. Figure 4(b) is the surface plot of figure 4(a). The 3D has the lowest value of $305 \mathrm{~m}$ and the highest value of $360 \mathrm{~m}$ as indicated by colour scale bar.



Figure 5: (a) contour plot of orthometric height via gravimetric geoid and ellipsoidal height and (b) surface plot

Figure 5 is the contour plot of orthometric height obtained via gravimetric geoid and ellipsoidal height the data in Table 1 were used for the plotting. The minimum and maximum contour values are $290 \mathrm{~m}$ an $350 \mathrm{~m}$ at $2 \mathrm{~m}$ grid interval. The method used in plotting Figure 5 was adopted. Figure 5 (b) is the surface plot of Figure 5 (a) with the lowest and highest values as $290 \mathrm{~m}$ and $350 \mathrm{~m}$ as indicated on the colour scale bar. 


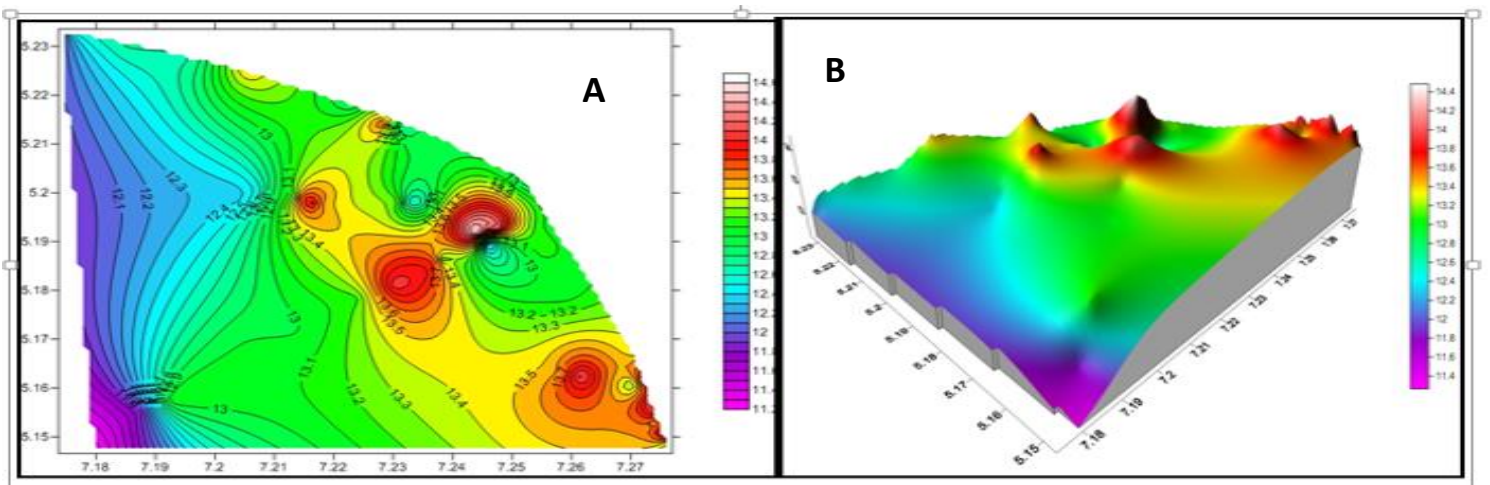

Figure 6: Contour plot of gravimetric geoidal undulation (a) and surface plot (b)

Figure 6 is a contour plot of gravimetric geoidal undulation computed via Stokes integral. The data in Table 1 were used for the plotting. The minimum and maximum contour values are $11.2 \mathrm{~m}$ and $14.6 \mathrm{~m}$. The contour were plotted with Surfer 11 software applying kriging gridding method at $0.15 \mathrm{~m}$ contour interval. Figure 6 (b) is the surface plot of Figure 6 (a) with minimum and maximum values of $11.4 \mathrm{~m}$ and $14.4 \mathrm{~m}$ as shown on the colour scale bar.

\section{Conclusion}

The research has attempted to carry out the determination of orthometric height using a gravimetric approach. In order to determine orthometric height for the study area, the geoidal quantity $\mathrm{N}$ was computed by applying classical Stokes integral. The ellipsoidal heights were obtained from the processed GPS observations using South GNSS processing software. The orthometric heights $(\mathrm{H})$ were determine by computing the difference between the tailored geoid height $\left(\mathrm{N}^{\text {Taylor }}\right)$ and the ellipsoidal heights $\left(\mathrm{h}_{\mathrm{GPS}}\right)$. Analysis of the results obtained, shows a standard deviation value of $10.6121 \mathrm{~m}$ and standard error value as $1.38159 \mathrm{~m}$ which is considered insignificant for the satisfactory accuracy of orthometric height within the study area. The result obtained produced contour plot and digital elevation model of the study area. The gravimetric method has proven to be an indispensable method for determination of orthometric heights.

\section{Reference}

Alaa A. Hussein, Faleh H. Mahmood (2016). Determination local geoid Heights Using RTK-DGPS/Leveling and transformation methods. Iraqi Journal of Science, Vol.57, No.2C, pp: 1604-1611

Amal M. A., (2016). Determination of the Geoid Height (Geoid Undulation) By Using Modern Surveying Technologies Applied Research Journal Vol.2, Issue, 10, pp.403-411

Featherstone, W. E.; M. C. Dentith and J.F. Kirby. (1998). Strategies for the accurate determination of Orthometric Heights from GPS. Survey review. 34(267):278-296

Fubara, D. M. J. (2007). The relevance of gravity measurements in geodesy and geodynamics. Lead paper presented at the workshop on the relevance of gravity measurements in geodesy and geodynamics organized by Centre for Geodesy and Geodynamics, National Space Research and Development Agency, Toro, Bauchi State Heiskanen, W., and Moritz, H. (1967). Physical Geodesy. London: W.H Freeman and Company.

Huang, J. and Veronneau, M. (2004). GPS-leveling and CHAMP\&GRACE geoid models. Advances in Geosciences, pp: 16, doi: $10.4095 / 216690$.

Michael I. O, and Franklin I. A. (2017). Hydro geophysical Study of Parts of Charnockite Terrain of Akure Southwestern Nigeria. Global Journal of Pure and Applied Sciences Vol.23, 2017: pp: 107-121

Moka, E. C. (2011). Requirement for the determination of orthometric heights from GPS - determined heights. Contemporary issues in surveying and Geoinformatics. Edited by F.A. Fajemerakum

Uzodinma, V. N., Oguntuase J. O, Onah E., Chike C., and Ehigiator R (2014). Validation of EGM2008-Based Orthometric Heights in a Micro-Environment in Nigeria. FIG Congress 2014 Engaging the ChallengesEnhancing the Relevance Kuala Lumpur,Malaysia

Okeke. F, and Nnam V. (2016). Determination of best fitting Geoid for Enugu state-Gravimetric Approach. FIG Working Week: Recovery from Disaster. Christchurch, NewZealand.

Ono, M. N. (2009). On Problems of coordinates, coordinate systems and Transformation Parametes in local map Production, updates and Revisons in Nigeris. FIG Working Week 2009: Surveyor's Key Role in Accelerated Development. Ellat, Israel.

Peprah, M. S. and Kumi, S. //A. (2017). Appraisal of Methods for Estimating Orthometric Heights Journal of Geosciences and Geomatics. 5(3), 96-108. DOI: 10.12691

Shrivastava, P., Sahoo, L. and Stalin, M. (2015). Geoid Models for Indian Territory. IJSRSET, Vol. 1 No. 4, Pp 180-187. 